\title{
Treagust, David F. and Tsui, Chi-Yan (Ed.) (2013). Multiple Representations in Biological Education, Models and Modeling in Science Education (Volume 7). Dordrecht, Heidelberg, New York, London: Springer. 390 p. ISBN: 978-94-007-4191-1 (print version)
}

Reviewed by Gregor TORKAR ${ }^{1}$

Why should we read this book? I can think of at least two major reasons why the book entitled Multiple Representations in Biological Education, published by Springer in 2013 in the Models and Modeling in Science Education series, is essential reading for anyone involved in biology education.

The first has to do with the lifestyle of people, especially youth, in contemporary societies. The situation in economically undeveloped, developing, and devel-

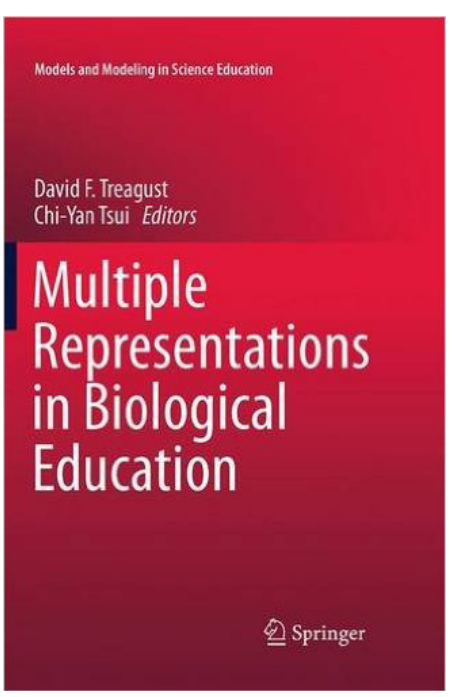
oped societies around the world is far from equal; nevertheless, there is a common trend of peoples' growing displacement from the natural environment. Today, on average, children and adolescents spend less time outdoors, playing and discovering things, resulting in a wide range of problems that Richard Louv (2005) labelled 'nature deficit disorder'. The term is receiving increasing attention in the relevant literature. Direct contact with living things in natural environments provides information and experiences that learners use in school as a solid base to construct a deeper understanding of the world. Unfortunately, the current state of primary and secondary schooling remains unchanged, and learning outcomes are to the greatest extent still realised in the classroom. The content of the book provides a synthesis of international research on using visualisations, analogies and other means of external representations to improve higher-order learning. In particular, modern modes of representation, like virtual reality, might influence narrowing the gap described above. However, this cannot replace direct experiences in nature!

1 University of Ljubljana, Faculty of Education, Slovenia; gregor.torkar@pef.uni-lj.si. 
Second, an equally or even more important reason for studying the content of the book is, in my opinion, the current position of biology as a natural science. In recent decades, biology has evolved from classical (descriptive) to modern (explanatory) science. Following the era of engineering (19th century), chemistry and physics (2oth century), biology is starting to play a key role in tackling the global/complex problems of the 21st century. Biology education is following these changes. For example, the Biological Sciences Curriculum Study (2009) has identified six unifying principles in biology that can help organise the biological content of a course and the patterns and processes of natural phenomena in the living world: (1) evolution, (2) Interactions and interdependence, (3) genetic continuity and reproduction, (4) growth, development and differentiation, (5) energy, matter and organisation, (6) maintenance of a dynamic equilibrium. Similarly, in the book under review, The Biological Sciences Curriculum Study's approach to biology is named 'the domain knowledge of biology' and described as a body of extensive and complex knowledge about life and living organisms, which incorporates the integration of other disciplines, particularly chemistry, physics, and mathematics. Therefore, illustrating teaching and learning strategies to enhance students' ability to construct mental models and internal representations with the use of multiple external representations will assist them in understanding biology-related issues, such as societal problems about food, the environment, energy and health.

This book consists of 19 chapters arranged in three thematic parts. Part I is entitled Role of Multiple Representations in Learning Biology and consists of six chapters. Authors discuss the important roles multiple external representations have in biology education in order to make learning and teaching most effective. Part II is entitled Implications for Biology Teaching and Teacher Education and consists of seven chapters, which mainly provide examples of teaching biology with multiple external representations. Part III is entitled Assessment of Learning and Teaching with Multiple Representations and consists of six chapters. This part provides some methods on how to assess learning with multiple external representations.

First, let me point out the introductory chapter, written by editors David Franklin Treagust and Chi-Yan Tsui, which introduces the theoretical perspectives of this book. It is a 'must read' chapter for understanding the importance multiple external representations play in biological education. Especially valuable is the three-dimensional model or the cube model for learning biology with multiple external representations. The first dimension represents modes of representation like pictures, diagrams, graphs and equations, organised on the cube according to increasing abstraction. The second dimension represents four levels 
of representation. What is unique for biology learning is complex, hierarchical organisation of life and nested knowledge domain, which gives, in their opinion, rational for using four learning levels of representation (macro, micro, submicro, and symbolic levels) instead of the three levels (macro, submicro and symbolic levels) proposed by Johnstone (1991) in chemistry education. The third, previously discussed, dimension represents the domain knowledge of biology.

The following 17 chapters in the book can be studied in no particular order. These chapters are a collection of empirical studies (e.g. Secondary Students' Understanding of Genetics Using BioLogica: Two Case Studies; Deconstructing and Decoding Complex Process Diagrams in University Biology) and theoretical expositions (e.g. Pictures in Biology Education; Possible Constraints of Visualisation in Biology: Challenges in Learning with Multiple Representations). The editors explained that ' $[. .$.$] these chapters differ in both the content$ areas and contexts within which learning and teaching take place in different languages in more than ten countries' (p. 350). In the final chapter of the book, the editors conclude by highlighting important aspects of presented research which can contribute to biology teacher education in terms of developing teachers' pedagogical content knowledge. Pedagogical content knowledge offers ways of engaging students in the content and ways how specific content can be successfully taught (Loughran et al., 2008).

Overall, the book makes very interesting reading, containing a great deal of high quality information. On the back cover, the most important aspects are well articulated: 'Addressing a major gap in the literature, the volume proposes a theoretical model for advancing biology educators' notions of how multiple external representations (MERs) such as analogies, metaphors and visualisations can best be harnessed for improving teaching and learning in biology at all pedagogical levels.' To conclude, I highly recommend this book to student teachers, teachers and researchers in biology education and related disciplines.

\section{References}

BSCS (Biological Sciences Curriculum Study) (2009). The Biology Teacher's Handbook (4th edition). Arlington, Virginia: NSTA press.

Johnstone, A. H. (1991). Why is science difficult to learn? Things are seldom what they seem. Journal of Computer Assisted Learning, 7(2), 75-83.

Loughran, J., Mulhall, P., \& Berry, A. (2008). Exploring pedagogical content knowledge in science teacher education. International Journal of Science Education, 30(10), 1301-1320.

Louv, R. (2005). Last child in the woods: saving our children from nature-deficit disorder. Chapel Hill: Algonquin Books. 